\title{
ARE THERE ANY DIFFERENCES IN THE AGILITY PERFORMANCE TESTS AMONG GOALKEEPERS DEPENDING ON THE TYPE OF SURFACE? A CROSSOVER STUDY
}

original paper

(c) University School of Physical Education in Wroclaw

DOI: https://doi.org/10.5114/hm.2019.85093

\section{LEONARDO DOS SANTOS OLIVEIRA ${ }^{1}$, VINÍCIUS SERRANO BRAZ DE HOLANDA ${ }^{1}$, JORGE LUIZ DE BRITO-GOMES ${ }^{2}$, NAYARA ELIS CABRAL PONTES ${ }^{1}$,} GEOVANI GARCIA DE SOUZA ${ }^{3}$, RODRIGO RAMALHO ANICETO ${ }^{4}$, JORGE PÉREZ-GÓMEZ ${ }^{5}$

\author{
${ }^{1}$ Federal University of Paraíba, João Pessoa, Brazil \\ ${ }^{2}$ Vale do São Francisco University, Petrolina, Brazil \\ ${ }^{3}$ Integrated Faculties of Patos, Patos, Brazil \\ ${ }^{4}$ Federal Institute of Education, Science and Technology of Rio Grande do Norte, Currais Novos, Brazil \\ ${ }^{5}$ University of Extremadura, Cáceres, Spain
}

\section{ABSTRACT}

Purpose. The aims of the study were: (a) to compare agility in the T-test (TT) and square test (ST) on different surfaces (natural grass $v s$. wood); (b) to compare agility performance in soccer and futsal young male goalkeepers.

Methods. In a crossover study, 8 soccer (age: $16 \pm 2$ years, body mass: $68.5 \pm 10.5 \mathrm{~kg}$, height: $1.69 \pm 0.4 \mathrm{~m}$, relative body fat mass: $22.4 \pm 6.5 \%$ ) and 8 futsal (age: $16 \pm 1$ years, body mass: $67.7 \pm 8.4 \mathrm{~kg}$, height: $1.70 \pm 0.4$ m, relative body fat mass: $21.0 \pm 6.1 \%)$ goalkeepers randomly performed TT and ST on both surfaces. All comparisons were adjusted for body mass and relative body fat mass.

Results. Surface had a slight effect $(0.066 \leq d \leq 0.163)$ on agility in both tests irrespective of the sport $\left(\mathrm{TT}_{\text {grass }}: 10.90 \pm 1.04 \mathrm{~s}\right.$, $\left.\mathrm{TT}_{\text {wood }}: 10.80 \pm 0.96 \mathrm{~s}, \mathrm{ST}_{\text {grass }}: 5.82 \pm 0.32 \mathrm{~s}, \mathrm{ST}_{\text {wood }}: 5.87 \pm 0.36 \mathrm{~s}, p>0.05\right)$. No differences were found in agility performance between soccer $\left(\mathrm{TT}_{\text {grass }}: 11.10 \pm 0.23 \mathrm{~s}, \mathrm{TT}_{\text {wood }}: 11.10 \pm 0.28 \mathrm{~s}, \mathrm{ST}_{\text {grass }}: 5.75 \pm 0.08 \mathrm{~s}, \mathrm{ST}_{\text {wood }}: 5.85 \pm 0.14 \mathrm{~s}\right)$ and futsal (TT ${ }_{\text {grass: }}$ : $\left.10.60 \pm 1.07 \mathrm{~s}, \mathrm{TT}_{\text {wood }}: 10.50 \pm 0.90 \mathrm{~s}, \mathrm{ST}_{\text {grass }}: 5.81 \pm 0.31 \mathrm{~s}, \mathrm{ST}_{\text {wood }}: 5.84 \pm 0.31 \mathrm{~s}\right)$ goalkeepers, regardless of the test or surface $(p>0.05)$. There were strong relationships among the conditions $(0.69 \leq r \leq 0.96)$. Moreover, the tests applied on different surfaces systematically produced similar results, and interchange of test surfaces was supported by parallel reliability.

Conclusions. Surface effect for both tests does not seem enough to induce statistical differences in the agility of soccer and futsal young male goalkeepers. Goalkeepers' agility performances were similar in both sports.

Key words: adolescent, athletic performance, soccer, futsal, physical fitness, sports

\section{Introduction}

Agility is an essential feature in the athletic performance of soccer and futsal players [1-4]. Although these sports exhibit comparable technical characteristics, the dynamics of the game and hence physical demands are different [3, 4]. For goalkeepers, agility performance supports multiple game actions, since goalkeepers must respond to the different movements of the ball or players during the match [5, 6]. In addition to facing a reduced court size and ball size, futsal goalkeepers are required to perform a higher number of high-intensity actions in comparison with their soccer counterparts [3, 6, 7]. As a consequence, it has been argued that agility differences should exist between goalkeepers of these sports [6, 8, 9].

Investigations on agility have reported conflicting evidence. Some studies have shown similar results between soccer goalkeepers and other players [10], while other research has indicated reduced performance in goalkeepers $[11,12]$. In young male goalkeepers, agility seems to be influenced by age and experience $[1,13-15]$.

Correspondence address: Leonardo dos Santos Oliveira, Laboratório de Cineantropometria, Universidade Federal da Paraíba, Cidade Universitária, João Pessoa-PB, Brazil, CEP: 58051-900, e-mail: leosoliveira@uol.com.br

Received: January 15, 2019

Accepted for publication: April 10, 2019

Citation: Oliveira L, Holanda VSB, Brito-Gomes JL, Pontes NEC, Souza GG, Aniceto RR, Pérez-Gómez J. Are there any differences in the agility performance tests among goalkeepers depending on the type of surface? A crossover study. Hum Mov. 2019;20(4):59-67; doi: https://doi.org/10.5114/hm.2019.85093. 
U-14 soccer goalkeepers performed worse in agility tests than their U-19 peers [13]. Likewise, U-13 futsal goalkeepers have shown less agility than U-15 and U-17 age groups [14]. Despite this, scientific research on young goalkeepers is scarce, especially with regard to futsal [1, 3]. Additionally, agility performance analyses between soccer and futsal young goalkeepers have not been performed yet.

Agility tests have usually been applied in indoor environments (e.g., gymnasium and hard or soft courts) and they can be sport-dependent [5, 16]. However, in sports practice, coaches and athletes have provided adapted tests for use in their training routines. Safeguarded the ecological validity, this can constitute an alternative approach for testing batteries based on the feasibility of physical environment, material resources, and weather conditions [17]. Nevertheless, surfaces vary among sports and within sports; mechanical responses of the surface provide different friction levels, and distinct types of forces experienced by the player (e.g., ground reaction force) can compromise the measurements [18-22].

Previous studies have assessed agility and sprint performance on different surfaces in adult soccer players [21-24]. Hughes et al. [21] and Stone et al. [24] showed that surface type did not affect the decrease in agility performance, whereas López-Fernández et al. [22] demonstrated that differences in shock absorption and energy return between artificial turf and natural grass might be sufficient to affect high-intensity turning and cutting movements. In turn, Gains et al. [23] reported that sprint speed was similar between artificial turf and natural grass, but change-of-direction speed might be higher on field turf. Then, presumably different surfaces may provide modifications in agility performance. Nevertheless, studies devoted to comparing agility tests on grass and wooden surface are sparse and interchange of these alternate forms can be supported by establishing their parallel reliability [25, 26].

In soccer, the T-test (TT) is one of the most applied methods for agility performance assessment $[12,16$, 27]; it includes a T-shaped trajectory with a $90-180^{\circ}$ change of direction. In contrast, the agility square test (ST) is an alternative method that comprises shorter run distances (4-meter square) with $45^{\circ}$ turns [28]. ST seems to properly reflect the goalkeeper's performance and is used in a soccer and futsal setting, although more studies are required before a clear evidence is established. It is important to highlight that the changes of direction in the tests interact with the traction between a soccer/futsal cleat and a playing surface, and that may influence the performance of the goalkeeper $[18,19]$. Another drawback is that young futsal goalkeepers have not been assessed by TT yet $[6,13]$.

The rationale of this study relies upon the fact that there is no consensus about the effect of different surfaces on agility performance in different tests and that there is a possible difference between soccer and futsal goalkeepers. Thus, the aims of the study were: (a) to compare the agility in TT and ST on different surfaces (natural grass vs. wood), and (b) to compare the agility performance between soccer and futsal young male goalkeepers. The proposed hypotheses were: (a) agility performance is better on the wooden surface for both tests, and (b) futsal goalkeepers are more agile than their soccer counterparts. Considering that available data regarding goalkeeper-specific skills are limited $[1,15,29]$ and that goalkeepers' performance is related to agility $[1,3,4]$, a better understanding of the features related to this variable will assist coaches, athletes, and researchers to improve the assessment approaches in sports, as well as in experimental designs.

\section{Material and methods}

\section{Participants}

Overall, 8 soccer and 8 futsal young male goalkeepers were recruited from two Brazilian northeast teams (regional top-level). A priori sample size was estimated by the G*Power 3.1 (Franz Faul, Germany) for a mean difference of 1.0 (standard deviation $[S D]=0.5$ ) in agility (in seconds) between the sports/surfaces, considering $\alpha=0.05$ and power $(1-\beta)=0.8$, in accordance with Beck [30] and Faul et al. [31]. Thus, a minimum of 6 participants by sport was needed. The inclusion criteria were: (a) being apparently healthy by the Physical Activity Readiness Questionnaire, (b) having at least 2 years of experience at a competitive regional level, and (c) participating in technical-tactical training 3 or more days per week. Participants who used ergogenic resources or with osteomyoarticular injuries were excluded.

\section{Experimental design}

This is an experimental crossover study. After anthropometric measurements, the goalkeepers performed TT and ST on natural grass (soccer field) and wooden (indoor court) surface on the same day. In order to familiarize themselves with those surfaces, the goalkeepers performed one attempt in each condition. The rest interval between the tests for each surface was 5 min- 
utes. The order of tests and surfaces was randomly established for each participant by the Research Randomizer software [32]. Figure 1 depicts the design of the study.

\section{Anthropometry and body composition}

Body mass was measured with digital scales (Sanny, Brazil) to the nearest $0.1 \mathrm{~kg}$. Height was determined with a portable stadiometer (Sanny, Brazil) to the nearest $0.01 \mathrm{~m}$. Triceps and subscapular skinfolds thickness were measured (in triplicate) by using a skinfold caliper (Cescorf, Brazil) to the nearest $0.1 \mathrm{~mm}$. All measurements were performed by a trained rater in accordance with standard procedures [33]. From a bicompartimental model, an estimation of relative body fat mass (BFM) was performed by applying the equation of Boileau et al. [34], which uses the sum of triceps and subscapular skinfolds ( $\Sigma 2 \mathrm{SF}$ ):

$$
\mathrm{BFM}(\%)=1.35 \cdot(\Sigma 2 \mathrm{SF})-0.012 \cdot(\Sigma 2 \mathrm{SF})^{2}-4.4
$$

Moreover, relative fat-free mass (FFM) was estimated:

$$
\text { FFM }(\%)=100-\text { BFM }
$$

\section{Agility measurement}

The assessment of the physical components of agility, which does not consider perceptive factors [35], was carried out by the TT and ST tests. These tests measure the ability to change direction quickly without losing balance [28, 36]. For standardization purposes, the goalkeepers wore soccer cleats (studded shoes) on the grass and indoor soccer cleats (non-studded shoes) on the wooden surface. Layout measurements (Figure 2) were performed with a fiberglass tape measure (Lufkin, USA) with a resolution of $0.1 \mathrm{~cm}$. Time was recorded by using a digital stopwatch (HS-3V-1R, Cassio Stopwatch, China) with a resolution of $0.01 \mathrm{~s}$ by the same trained rater. The goalkeepers were verbally encouraged and asked to perform the tests at maximum speed.

TT was applied in accordance with Semenick [36]. The goalkeepers were asked to cover a total distance

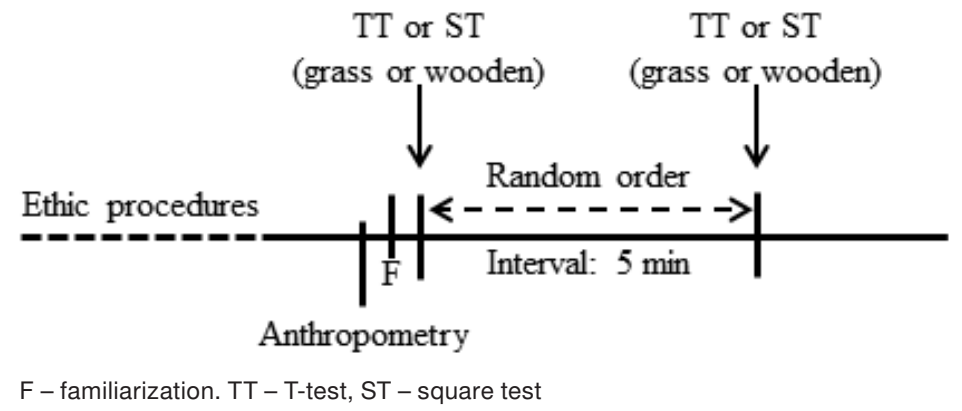

Figure 1. Design of the study
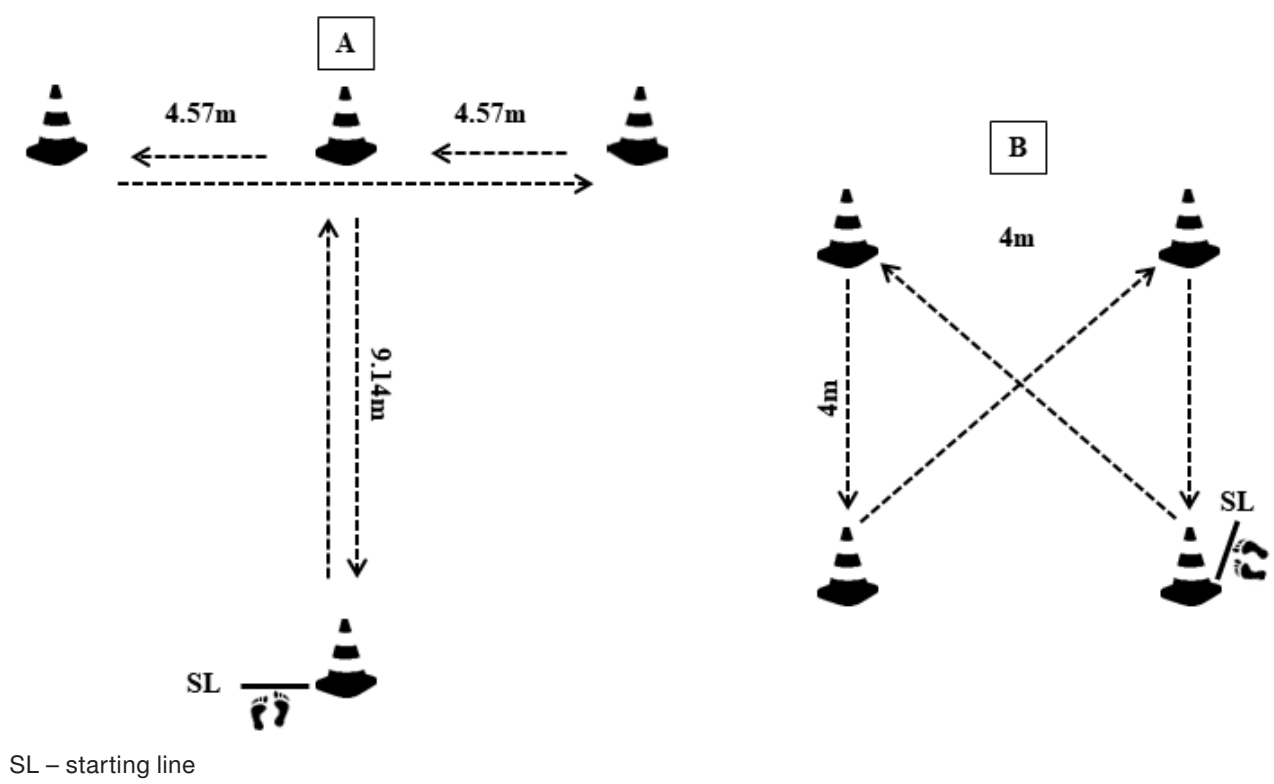

Figure 2. Layout of the agility tests. (A) T-test; (B) square test 
of $36.56 \mathrm{~m}$, forming a ' $\mathrm{T}$ ' shape with a $90-180^{\circ}$ change of direction, where a cone was placed at $9.14 \mathrm{~m}$ from the starting line and the others were placed at $4.57 \mathrm{~m}$ on both sides from the middle cone (Figure 2A). From the starting line, the goalkeepers sprinted $9.14 \mathrm{~m}$ and touched the middle cone. After that, they shuffled $4.57 \mathrm{~m}$ to the left, touched the left cone, and shuffled $9.14 \mathrm{~m}$ to touch the right cone. Then, the participants ran to touch the middle cone and, finally, returned to the starting line. The clock began and stopped when the goalkeepers crossed the starting line. The participants performed 2 attempts ( 2 minutes apart), and the best time was considered for statistical analysis.

ST was applied in accordance with Gaya and Gaya [28]. The test includes a $45^{\circ}$ change of direction. The goalkeepers were asked to cover a total distance of $19.31 \mathrm{~m}$; 4 cones were displayed forming a 4-meter square (Figure 2B). The participants ran diagonally (crossing the square) and touched the cone. Then, they touched the cone to their left and ran again to touch the cone diagonally. Finally, they ran towards the last cone, which corresponded to the starting line. The stopwatch began when the goalkeepers touched with their foot the inside of the square for the first time and stopped when they touched the $4^{\text {th }}$ cone with their hands $[28,37]$. The participants performed 2 attempts ( 2 minutes apart), and the best time was considered for statistical analysis.

\section{Statistical analysis}

Data were presented by mean $\pm S D$ and $95 \%$ confidence interval (CI). For agility performance, a coefficient of variation (CV, \%) was computed and interpreted as 'low dispersion' for $\mathrm{CV} \leq 10 \%$, 'high dispersion' for $\mathrm{CV} \geq 20 \%$, and 'moderate dispersion' for the range between the two, as proposed by Pomella et al. [38]. Anthropometric and body composition data were compared between sports by the independent $t$-test. A generalized estimating equation model with gamma distribution and log link function was used to examine differences in agility by sport and surface (it was adjusted for body mass and BFM). The first order autoregressive was selected as a working correlation matrix (robust estimator), and model selection (best overall fit) for agility was based on the lowest quasilikelihood under independence model criterion [39]. Normality of the raw residuals was checked by using $\mathrm{Q}-\mathrm{Q}$ plots and deemed plausible. The effect size was computed between sports $\left[d=\mathrm{t}_{\mathrm{i}} \cdot(2 / \mathrm{n})^{1 / 2}\right]$ and surfaces $\left[d=t_{c} \cdot(2 \cdot(1-r) / n)^{1 / 2}\right]$ as defined by Dunlap et al. [40], and interpreted as trivial for $d<0.20$, small for $d$ ranging $0.20-0.59$, moderate for $d$ ranging 0.60 1.19 , large for $d$ ranging 1.20-1.99, very large for $d$ ranging 2.00-3.99, and almost perfect for $d \geq 4.0$ [41]. Relationships between agility performance and conditions as well as body mass and BFM were verified by the Pearson's correlation coefficient $(r)$. A linear regression analysis was performed for TT and ST on each surface, with the agility on the wooden surface considered as the dependent variable. Additionally, the differences between the 2 surfaces (grass minus wood) were plotted against their mean value, and the limits of agreement were defined as the mean difference \pm $2 S D$ by the Bland-Altman analysis [26]. Statistical analysis was performed with the use of the IBM Statistical Package for the Social Sciences, version 25.0 (IBM Corp., Armonk, USA) and the MedCalc 18.6 software (MedCalc Software bvba, Ostend, Belgium). The results at $p<0.05$ were considered statistically significant.

\section{Ethical approval}

The research related to human use has complied with all the relevant national regulations and institutional policies, has followed the tenets of the Declaration of Helsinki, and has been approved by the ethics committee of the Federal University of Paraíba (No. 86164/12, CAAE: 01906112.6.0000.5188).

\section{Informed consent}

Informed consent has been obtained from all individuals included in this study and their legal guardians.

\section{Results}

Anthropometric and body composition characteristics (Table 1$)$ were similar between sports $(p>0.05)$; however, an intragroup variability for body mass and body composition was found, especially among soccer goalkeepers. No significant association was observed between body mass $(-0.30<r<-0.15)$ or BFM $(-0.15$ $<r<0.14)$ and agility performance in both tests.

In the correlation analysis (Table 2), strong significant relationships were found among conditions $(r>$ $0.69, p<0.05)$. From the linear regression between the surfaces, the $\mathrm{R}_{\text {adjusted }}^{2}=0.908$ for TT indicates that about $91 \%$ of the observed variance on the wooden surface can be explained by the grass scores $\left(\mathrm{F}_{(1,14)}=\right.$ $148.2, p=0.001$, mean square error $=0.29$ ). This model suggests that for every additional second in grass, wooden surface can be expected to increase by an average of 0.83 s (95\% CI: 0.69-0.98). On the other hand, the $\mathrm{R}_{\text {adjusted }}^{2}=0.673$ for ST indicates that only 
Table 1. Anthropometric and body composition data of young soccer and futsal goalkeepers

\begin{tabular}{lccc}
\hline Variable & Total $(n=16)$ & Soccer $(n=8)$ & Futsal $(n=8)$ \\
\hline Age (years) & $16 \pm 1(15.6-16.3)$ & $16 \pm 2(15.4-16.6)$ & $16 \pm 1(15.3-16.4)$ \\
Body mass (kg) & $67.6 \pm 9.2(62.7-72.5)$ & $68.5 \pm 10.5(59.7-77.2)$ & $66.7 \pm 8.4(59.7-73.7)$ \\
Height (m) & $1.69 \pm 0.4(1.67-1.72)$ & $1.69 \pm 0.4(1.65-1.73)$ & $1.70 \pm 0.4(1.67-1.73)$ \\
$\Sigma 2 S F(m m)$ & $26.0 \pm 9.1(21.1-30.9)$ & $27.0 \pm 9.3(19.2-34.8)$ & $25.1 \pm 9.4(17.2-32.9)$ \\
Body fat mass (\%) & $21.7 \pm 6.2(18.4-24.9)$ & $22.4 \pm 6.5(16.9-27.9)$ & $21.0 \pm 6.1(15.9-26.1)$ \\
Free-fat mass (\%) & $78.3 \pm 6.2(75.0-81.6)$ & $77.6 \pm 6.5(72.1-83.1)$ & $79.0 \pm 6.1(73.9-84.1)$ \\
\hline
\end{tabular}

Data presented as mean $\pm S D(95 \%$ confidence interval)

$\Sigma 2 \mathrm{SF}$ - sum of triceps and subscapular skinfolds

Table 2. Correlation analysis between agility tests on different surfaces $(n=16)$

\begin{tabular}{lccc}
\hline Test and surface & ST on wood & ST on grass & TT on wood \\
\hline TT on grass & $0.76(0.55-0.93)^{*}$ & $0.71(0.44-0.87)^{*}$ & $0.96(0.93-0.99)^{*}$ \\
TT on wood & $0.80(0.57-0.94)^{*}$ & $0.69(0.41-0.88)^{*}$ & \\
ST on grass & $0.83(0.64-0.97)^{*}$ & & \\
\hline
\end{tabular}

Data presented as Pearson's $r$ coefficient (95\% confidence interval)

* significant correlation at the 0.05 level

TT - T-test, ST - square test

about $67 \%$ of the observed variance on the wooden surface can be explained by the grass scores $\left(\mathrm{F}_{(1,14)}=\right.$ $31.8, p=0.001$, mean square error $=0.20$ ). This model proposes that for every additional second in grass, wooden surface can be expected to increase by an average $0.81 \mathrm{~s}$ (95\% CI: 0.50-1.12).

Bland-Altman analysis for TT (Figure 3A) and ST (Figure 3B) showed that the mean differences between surfaces were $0.07 \pm 0.33 \mathrm{~s}$ (95\% CI: $-0.103-0.253)$ and $-0.06 \pm 0.19 \mathrm{~s}$ (95\% CI: from -0.160-0.049), respectively. Only one score for each test was found out of the limits of agreement (Figures 3A and 3B).

The comparison between sports and surfaces in each agility test is depicted in Table 3 . Data presented low dispersion $(4.3 \leq \mathrm{CV} \leq 10)$, except for futsal goalkeepers in TT, where a moderate dispersion was found $(11.8 \leq \mathrm{CV} \leq 14.0)$. For TT, no significant differences were observed for sport $\left(\chi^{2}\right.$ wald $\left.=1.20, p=0.279\right)$, surface $\left(\chi^{2}\right.$ wald $\left.=0.99, p=0.318\right)$, or interaction $\left(\chi^{2}\right.$ wald $=1.37$, $p=0.241)$. Only a trivial surface effect was estimated for TT $(d=0.066)$. The futsal goalkeepers were $8.7 \%$ more agile than the soccer counterparts on the wooden surface $(d=-0.654)$ and $4.5 \%$ on the grass $(d=-0.390)$ in TT. Similarly, no significant differences were noted for $\operatorname{sport}\left(\chi^{2}\right.$ wald $\left.=0.00, p=0.997\right)$, surface $\left(\chi_{\text {wald }}^{2}=1.35\right.$, $p=0.245)$, or interaction $\left(\chi_{\text {wald }}^{2}=0.08, p=0.784\right)$ in ST. A small surface effect was estimated for ST $(d=0.163)$. The futsal goalkeepers were only $0.2 \%$ more agile than the soccer counterparts on the wooden surface $(d=$ $-0.039)$ and $1.0 \%$ less agile on the grass $(d=0.035)$ in ST.
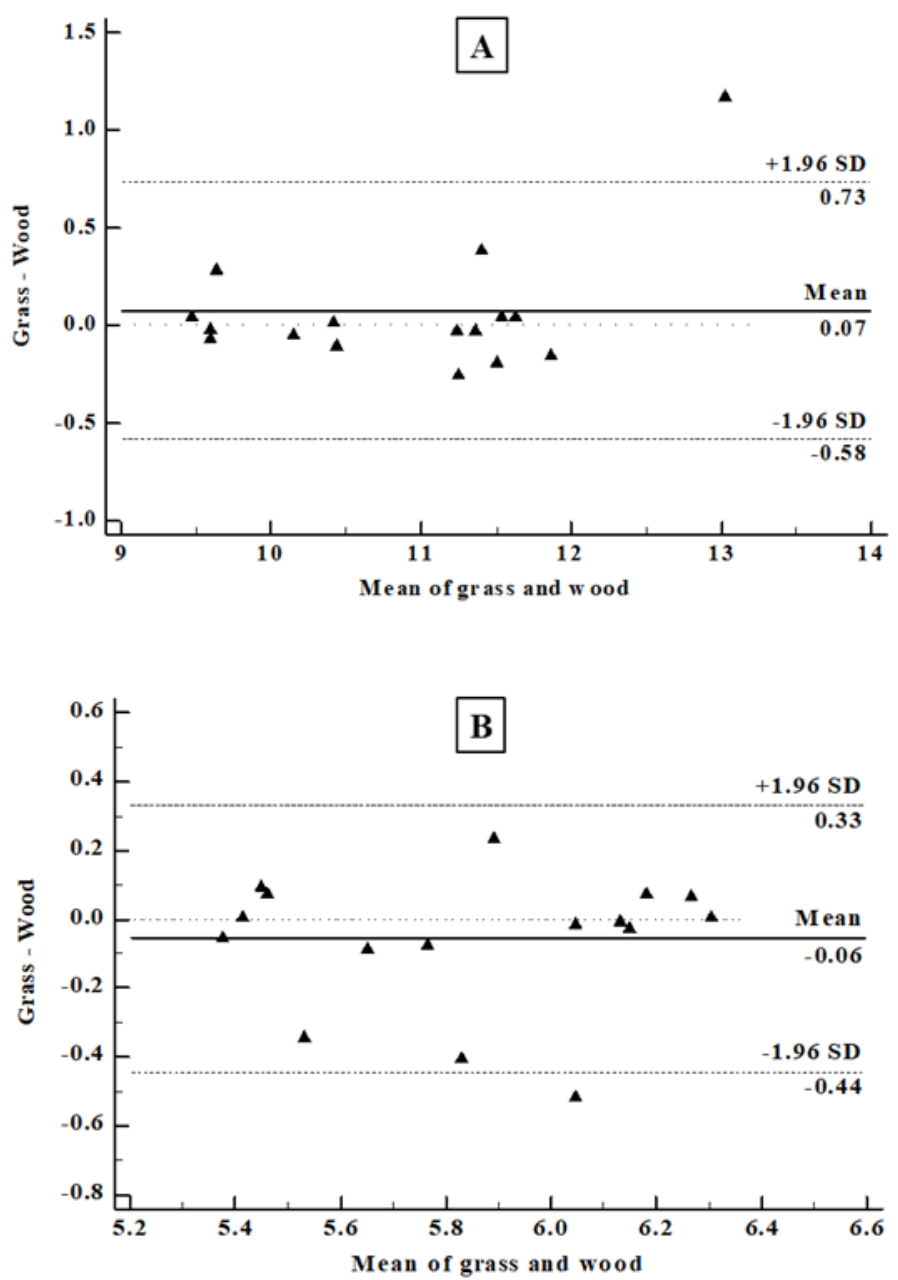

Figure 3. Bland-Altman plot analysis for agility difference (in seconds) between grass and wooden surface. (A) T-test; (B) square test 
L. Oliveira et al., Agility in soccer and futsal goalkeepers

Table 3. Agility tests on different surfaces in young soccer and futsal goalkeepers

\begin{tabular}{lcccc}
\hline Test & Surface & Total $(n=16)$ & Soccer $(n=8)$ & Futsal $(n=8)$ \\
\hline \multirow{2}{*}{ TT (s) } & Wood & $10.80 \pm 0.96(10.3-11.4)$ & $11.10 \pm 0.28(10.9-11.3)$ & $10.50 \pm 0.90(9.9-11.1)$ \\
& Grass & $10.90 \pm 1.04(10.4-11.5)$ & $11.10 \pm 0.23(10.9-11.2)$ & $10.60 \pm 1.07(9.9-11.4)$ \\
\hline \multirow{2}{*}{ ST (s) } & Wood & $5.87 \pm 0.36(5.7-6.0)$ & $5.85 \pm 0.14(5.7-6.0)$ & $5.84 \pm 0.31(5.6-6.1)$ \\
& Grass & $5.82 \pm 0.32(5.6-6.0)$ & $5.75 \pm 0.08(5.6-6.0)$ & $5.81 \pm 0.31(5.6-6.0)$ \\
\hline
\end{tabular}

Data presented as mean $\pm S D$ (95\% confidence interval). Agility performance adjusted for body mass and body fat mass (\%) TT - T-test, ST - square test

\section{Discussion}

The current investigation compared agility tests (TT and ST) on different surfaces (natural grass vs. wood) and goalkeeper's agility performance in soccer and futsal. The hypotheses that stated agility performance is better on the wooden surface for both tests and that futsal goalkeepers are more agile than the soccer counterparts were refuted. The results indicate that: (a) the surface had a slight effect on the agility scores in both tests irrespective of sport, and (b) the soccer and futsal young goalkeepers exhibited similar agility performance regardless of the test or surface. Although establishing the surface comparison does not directly generalize our findings in the sport practice, the results seem to have interesting applications in the context of the goalkeepers' dynamics for both sports.

The available data concerning goalkeeper-specific skills are scarce, particularly for young players $[1,15$, 29]. Our study is a pioneer in performing TT and ST in young soccer goalkeepers and provides a useful reference of agility performance between soccer and futsal Brazilian goalkeepers (regional top-level) by 2 different tests on grass and wooden surfaces. Considering an intragroup variability for the body mass and body composition and the influence of BFM on the agility scores for goalkeepers in specific agility tests [4], we adjusted the sport-surface interaction by taking into account these variables. Even so, futsal goalkeepers presented a moderate dispersion in TT. In addition, the randomized order of the testing applications and surfaces was relevant to minimize the 'learning effect' on the goalkeepers' agility performance [16].

It is well known that the different surfaces used in sports can have a significant effect on performance [18-23]. The tests presented a strong association among them, with mean differences between surfaces near to zero. It assumes that any variation in the observed results for different surfaces was not due to random error and it has not a significant effect on the agreement $[25,26]$. Furthermore, the proportion of variance that the 2 surfaces had in common ranged $67-91 \%$, and the surface effect on the goalkeepers' agility performance was negligible for both tests [41, 42]. Therefore, this suggests that the TT and ST performed on different surfaces are systematically producing similar results, and that interchange of these test surfaces was supported by the parallel reliability presented $[25,26]$.

Many studies have compared agility or sprint performance between natural grass and artificial turf [21-24] and conflicting evidence has been found. The slight surface effect on agility performance corroborated previous investigations that used the soccersimulation protocol [21], the L-agility run [24], and the pro-agility [23] tests; in those investigations, mechanical properties of the test surfaces were not measured. In contrast, López-Fernández et al. [22] indicated that shock absorption and energy return differences between natural grass and artificial turf were enough to affect turning performance in amateur soccer players, but too weak to be taken into account by coaches. Since grass and wooden surface present important differences regarding shock absorption and energy return [18], part of the variations on agility performance could be explained with these features. However, these small differences in performance may not be significant enough to be considered in agility assessment [22] if a thorough analysis is not performed.

Another interesting issue is related to differences in the changes of direction [21]. In ST, the goalkeepers performed acceleration and deceleration with $45^{\circ}$ turns. Keshvari and Senner [19] reported significant differences between translational traction and rotational traction in 3 samples of artificial surfaces (polypropylene-based surfaces) and a single indoor soccer cleat (futsal). For ST, the shared variance between surfaces was only about $67 \%$. In comparison with TT (90-180 ${ }^{\circ}$ turns), it is possible that this difference can be attributed to translational traction and rotational 
traction, but we did not measure these mechanical properties. In addition, some studies have suggested that a lower coefficient of friction is generated between soccer cleats and the grass, which allows for a greater sliding surface when the goalkeeper slows down and changes direction [18, 20].

Despite the limited frequency with which goalkeepers perform high-intensity actions, especially in soccer, these actions are very decisive for the match outcome $[3,43,44]$. In a defensive scenario, goalkeepers perform multi-directional actions in short distances (e.g., 1-on-1, shots, sprints with dives/jumps) $[13,15$, 43, 44]. Di Salvo et al. [43] reported that professional soccer goalkeepers performed about 10 high-speed actions and the distance covered sprinting was about $11 \mathrm{~m}$. In turn, Goliński et al. [44] demonstrated that a 1-on-1 game was characterized as a high-intensity activity for soccer goalkeepers. Nevertheless, hardly any data are available on the actions of futsal goalkeepers [3] for more comparisons. TT and ST present 4 and 3 changes of direction and the maximum sprint distance is about $9 \mathrm{~m}$ (including lateral movements) and $6 \mathrm{~m}$, respectively. Thus, whereas both tests are not goalkeeper-specific agility tests, they seem to be in accordance with goalkeepers' demands (e.g., number of changes of direction, sprint distances, types of displacement) [3, 4, 43].

Our results may still have been influenced by the characteristics of the sample, which included young goalkeepers who could have been less able to perform the agility tests at high speeds than professional goalkeepers [16, 22]. This is reinforced by the fact that agility is considered capable of distinguishing between higher-skilled players and their lesser-skilled counterparts [2]. Moreover, although some goalkeepers can already have experienced both sports [45], agility performance may have been impaired by using specific cleats for each surface, which can provide unusual dynamics to the player. While the conditions of grass or wood surfaces affect the loads imposed on the goalkeeper in the tests, the footwear will also be influential since it acts as a link in the interaction of friction $[18,19]$.

In our study, despite a slight advantage for futsal goalkeepers regardless of the surface (except for the TT on the grass), there was no significant difference between sports. Agility differences between soccer and futsal young male goalkeepers are not clear since previous studies have compared them with other playing positions within the same sport [10-12,15] or reported results for female players [9] or adult age groups [6]. Benvenuti et al. [9] showed that agility performance results from a planned agility test were similar between futsal and soccer adult female players. Likewise, Milanović et al. [6] applied several agility tests and concluded that the results obtained by male professional players in these 2 sports were very similar in terms of agility performance. Thus, our findings are in line with those in which game characteristics do not seem to influence the agility performance assessed by tests that do not consider perceptive factors.

Even though more specific protocols for soccer goalkeepers have been reported previously [15], ST seems to be an interesting test for assessing different physical components of agility in these sports, and it is already included in testing batteries for talent identification [28, 37]. However, agility performance can present differences between hand timer and electronic timer on distinct surfaces [23] and, despite the external validity, the use of a stopwatch implies restrictions and requires trained raters. Furthermore, although biological maturity status contributes relatively little to variation in soccer skills results [46], the lack of stage of puberty data was another limitation of this study.

As main practical implications, we may highlight, in the case of restrictions such as the physical environment, material resources, or unfavourable weather conditions (e.g., strong winds, rain, excessive heat), that the TT and ST that are performed on grass or wooden surface seem to be interesting alternatives. However, our results cannot be generalized to any grass or wooden surface. Moreover, the need to monitor the development of multi-directional movements in short distances among youth goalkeepers also seems to be relevant, since it allows coaches to identify weaknesses (e.g., non-preferred-side sprint performance) and to provide specific training in order to obtain performance improvements.

\section{Conclusions}

Despite the lack of data related to mechanical properties of the surface-footwear interaction, our findings suggest that the surface effect in TT or ST does not seem to be enough to induce differences in the agility of soccer and futsal young male goalkeepers. In addition, even considering the moderate dispersion for futsal goalkeepers in TT, goalkeepers' agility performance was similar between sports regardless of the test or surface. Although there are strong relationships between different conditions, respecting the principle of specificity in agility assessment is relevant. Future research could consider the influence of mechanical properties of the surface-footwear interaction, athletes' ex- 
perience on each surface, the number of multi-directional movements in agility tests, as well as an increase in the number of goalkeepers analysed per sport.

\section{Acknowledgements}

The authors express special thanks to the teams and the reviewers of this work.

\section{Disclosure statement}

No author has any financial interest or received any financial benefit from this research.

\section{Conflict of interest}

The authors state no conflict of interest.

\section{References}

1. Ziv G, Lidor R. Physical characteristics, physiological attributes, and on-field performances of soccer goalkeepers. Int J Sports Physiol Perform. 2011;6(4):509524; doi: 10.1123/ijspp.6.4.509.

2. Paul DJ, Gabbett TJ, Nassis GP. Agility in team sports: testing, training and factors affecting performance. Sports Med. 2016;46(3):421-442; doi: 10.1007/s40279015-0428-2.

3. Naser N, Ali A, Macadam P. Physical and physiological demands of futsal. J Exerc Sci Fit. 2017;15(2):7680; doi: 10.1016/j.jesf.2017.09.001.

4. West J. A review of the key demands for a football goalkeeper. Int J Sports Sci Coach. 2018;13(6):12151222; doi: 10.1177/1747954118787493.

5. Sheppard JM, Young WB. Agility literature review: classifications, training and testing. J Sports Sci. 2006;24(9): 919-932; doi: 10.1080/02640410500457109.

6. Milanović Z, Sporiš G, Trajković N, Fiorentini F. Differences in agility performance between futsal and soccer players. Sport Sci. 2011;4(2):55-59.

7. Vaeyens R, Lenoir M, Williams AM, Philippaerts RM. Mechanisms underpinning successful decision making in skilled youth soccer players: an analysis of visual search behaviors. J Mot Behav. 2007;39(5):395-408; doi: 10.3200/JMBR.39.5.395-408.

8. Gorostiaga EM, Llodio I, Ibáñez J, Granados C, Navarro I, Ruesta M, et al. Differences in physical fitness among indoor and outdoor elite male soccer players. Eur J Appl Physiol. 2009;106(4):483-491; doi: 10.1007/ s00421-009-1040-7.

9. Benvenuti C, Minganti C, Condello G, Capranica L, Tessitore A. Agility assessment in female futsal and soccer players. Medicina (Kaunas). 2010;46(6):415420; doi: 10.3390/medicina46060058.

10. Deprez D, Fransen J, Boone J, Lenoir M, Philippaerts R, Vaeyens R. Characteristics of high-level youth soccer players: variation by playing position. J Sports Sci. 2015; 33(3):243-254; doi: 10.1080/02640414.2014.934707.

11. Gil SM, Gil J, Ruiz F, Irazusta A, Irazusta J. Physiological and anthropometric characteristics of young soccer players according to their playing position: relevance for the selection process. J Strength Cond Res. 2007;21(2): 438-445; doi: 10.1519/R-19995.1.

12. Towlson C, Cobley S, Midgley AW, Garrett A, Parkin G, Lovell R. Relative age, maturation and physical biases on position allocation in elite-youth soccer. Int J Sports Med.2017;38(3):201-209; doi:10.1055/s-0042-119029.

13. Knoop M, Fernandez-Fernandez J, Ferrauti A. Evaluation of a specific reaction and action speed test for the soccer goalkeeper. J Strength Cond Res. 2013;27(8): 2141-2148; doi: 10.1519/JSC.0b013e31827942fa.

14. Picanço LM, Silva JJR, Del Vecchio FB. Relationship between strength and agility in futsal players [in Portuguese]. Rev Bras Futsal Futeb. 2012;4(12):77-86.

15. Rebelo-Gonçalves R, Figueiredo AJ, Coelho-e-Silva MJ, Tessitore A. Assessment of technical skills in young soccer goalkeepers: reliability and validity of two goalkeeper-specific tests. J Sports Sci Med. 2016;15(3): 516-523.

16. Sporis G, Jukic I, Milanovic L, Vucetic V. Reliability and factorial validity of agility tests for soccer players. J Strength Cond Res. 2010;24(3):679-686; doi: 10.1519/JSC.0b013e3181c4d324.

17. Tucker P, Gilliland J. The effect of season and weather on physical activity: a systematic review. Public Health. 2007;121(12):909-922; doi: 10.1016/j.puhe.2007.04.009.

18. Dixon S, Fleming P, James I, Carré M (eds.). The science and engineering of sport surfaces. Abingdon: Routledge; 2015.

19. Keshvari B, Senner V. Comparison of shoe-surface tractions on various playing surfaces in futsal. Procedia Eng. 2015;112:267-272; doi: 10.1016/j.proeng.2015. 07.245 .

20. Sleat W, O’Donoghue P, Hughes M, Bezodis NI. The influence of natural grass surface hardness on path changes, locomotive movements and game events in soccer: a case study. Int J Perform Anal Sport. 2016; 16(1):216-233; doi: 10.1080/24748668.2016.11868882.

21. Hughes MG, Birdsey L, Meyers R, Newcombe D, Oliver JL, Smith PM, et al. Effects of playing surface on physiological responses and performance variables in a controlled football simulation. J Sports Sci. 2013; 31(8):878-886; doi: 10.1080/02640414.2012.757340.

22. López-Fernández J, Sánchez-Sánchez J, García-Unanue J, Felipe JL, Colino E, Gallardo L. Physiological and physical responses according to the game surface in a soccer simulation protocol. Int J Sports Physiol Perform. 2018;13(5):612-619; doi: 10.1123/ijspp.2017-0570.

23. Gains GL, Swedenhjelm AN, Mayhew JL, Bird HM, Houser JJ. Comparison of speed and agility performance of college football players on field turf and natural grass. J Strength Cond Res. 2010;24(10):2613-2617; doi: 10.1519/JSC.0b013e3181eccdf8.

24. Stone KJ, Hughes MG, Stembridge MR, Meyers RW, Newcombe DJ, Oliver JL. The influence of playing surface on physiological and performance responses during and after soccer simulation. Eur J Sport Sci. 2016;16(1):42-49; doi: 10.1080/17461391.2014.984768. 
25. Portney LG, Watkins MP. Foundations of clinical research: applications to practice, $3^{\text {rd }}$ ed. Philadelphia: F.A. Davis Company; 2015.

26. Bland JM, Altman DG. Measuring agreement in method comparison studies. Stat Methods Med Res. 1999;8(2): 135-160; doi: 10.1177/096228029900800204.

27. Kutlu M, Yapıcı H, Yoncalık O, Çelik S. Comparison of a new test for agility and skill in soccer with other agility tests. J Hum Kinet. 2012;33:143-150; doi: 10.2478/ v10078-012-0053-1.

28. Gaya A, Gaya AR. Sports project Brazil: manual of tests and evaluation [in Portuguese]. Porto Alegre: UFRGS; 2016.

29. Rebelo-Gonçalves R, Coelho-e-Silva MJ, Severino V, Tessitore A, Figueiredo AJ. Anthropometric and physiological profiling of youth soccer goalkeepers. Int J Sports Physiol Perform. 2015;10(2):224-231; doi: 10.1123/ ijspp.2014-0181.

30. Beck TW. The importance of a priori sample size estimation in strength and conditioning research. J Strength Cond Res. 2013;27(8):2323-2337; doi: 10.1519/JSC. 0b013e318278eea0.

31. Faul F, Erdfelder E, Lang AG, Buchner A. G*Power 3: a flexible statistical power analysis program for the social, behavioral, and biomedical sciences. Behav Res Methods. 2007;39(2):175-191; doi: 10.3758/BF03193146.

32. Urbaniak GC, Plous S. Research Randomizer (version 4.0) [computer software]; 2013.

33. Stewart AD, Marfell-Jones M, Olds T, de Ridder JH. International standards for anthropometric assessment. Lower Hutt: International Society for the Advancement of Kinanthropometry; 2011.

34. Boileau RA, Lohman TG, Slaughter MH. Exercise and body composition of children and youth. Scand J Sports Sci. 1985;7(1):17-27.

35. Young WB, McDowell MH, Scarlett BJ. Specificity of sprint and agility training methods. J Strength Cond Res. 2001;15(3):315-319; doi: 10.1519/1533-4287(2001) 015<0315:SOSAAT>2.0.CO;2.

36. Semenick D. The T-test. Natl Strength Cond Assoc J. 1990;12(1):36-37.

37. Mello JB, Nagorny GAK, Haiachi MDC, Gaya AR, Gaya ACA. Projeto Esporte Brasil: physical fitness profile related to sport performance of children and adolescents. Rev Bras Cineantropom Hum. 2016;18(6): 658-666; doi: 10.5007/1980-0037.2016v18n6p658.

38. Pomella N, Wilhelm EN, Kolyva C, González-Alonso J, Rakobowchuk M, Khir AW. Common carotid artery diameter, blood flow velocity and wave intensity responses at rest and during exercise in young healthy humans: a reproducibility study. Ultrasound Med Biol. 2017;43(5):943-957; doi: 10.1016/j.ultrasmedbio.2016.12.018.

39. Cui J. QIC program and model selection in GEE analyses.StataJ.2007;7(2):209-220; doi:10.1177/1536867 X0700700205.

40. Dunlap WP, Cortina JM, Vaslow JB, Burke MJ. Metaanalysis of experiments with matched groups or repeated measures designs. Psychol Methods. 1996;1(2):170177; doi: 10.1037//1082-989X.1.2.170.

41. Hopkins WG, Marshall SW, Batterham AM, Hanin J. Progressive statistics for studies in sports medicine and exercise science. Med Sci Sports Exerc. 2009; 41(1):3-13; doi: 10.1249/MSS.0b013e31818cb278.

42. Cohen J. Statistical power analysis for the behavioral sciences. New York: Lawrence Erlbaum Associates; 1988.

43. Di Salvo V, Benito PJ, Calderón FJ, Di Salvo M, Pigozzi F. Activity profile of elite goalkeepers during football match-play. J Sports Med Phys Fitness. 2008;48(4): 443-446.

44. Goliński D, Muracki J, Wolański P, Klich S, Murawska-Ciałowicz E. Small-sided soccer game (1v1) in goalkeepers' training. Cent Eur J Sport Sci Med. 2016; 16(4):111-118; doi: 10.18276/cej.2016.4-12.

45. Ford PR, Carling C, Garces M, Marques M, Miguel C, Farrant A, et al. The developmental activities of elite soccer players aged under-16 years from Brazil, England, France, Ghana, Mexico, Portugal and Sweden. J Sports Sci. 2012;30(15):1653-1663; doi: 10.1080/ 02640414.2012 .701762$.

46. Malina RM, Cumming SP, Kontos AP, Eisenmann JC, Ribeiro B, Aroso J. Maturity-associated variation in sport-specific skills of youth soccer players aged 13-15 years. J Sports Sci. 2005;23(5):515-522; doi: 10.1080/ 02640410410001729928. 